\title{
Bilateral internal thoracic artery on the left side: A propensity score-matched study of impact of the third conduit on the right side
}

\author{
Michele Di Mauro, MD, Marco Contini, MD, Angela L. Iacò, MD, Antonio Bivona, MD, Massimo Gagliardi, MD, \\ Egidio Varone, MD, Paolo Bosco, MD, and Antonio M. Calafiore, MD
} Objective: This study was undertaken to evaluate long-term results of bilateral internal thoracic artery grafting
with saphenous vein or another arterial conduit as the third conduit.

\begin{abstract}
Methods: From September 1991 to December 2002, a total of 1015 patients underwent first isolated coronary artery bypass grafting for triple-vessel disease, with bilateral internal thoracic artery plus saphenous vein in 643 cases and bilateral internal thoracic artery plus arterial conduit in 372. A nonparsimonious regression model was built to determine propensity score, then sample matching (saphenous vein vs arterial conduit) was performed to select 885 patients (590 with saphenous vein, 295 with arterial conduit). Groups had similar preoperative and operative characteristics.
\end{abstract}

Results: Eight-year freedoms from cardiac death were significantly higher when saphenous vein was used $(98.6 \% \pm 0.5 \%$ with saphenous vein vs $95.3 \% \pm 1.3 \%$ with arterial conduit, $P=.009)$, but this difference was related exclusively to right gastroepiploic artery grafting $(94.5 \% \pm 1.6 \%$ vs saphenous vein, $P=.004)$. This difference disappeared for radial artery grafting $(97.6 \% \pm 1.6 \%$ vs saphenous vein, $P=.492)$. Cox analysis confirmed that supplementary gastroepiploic artery was an independent variable for lower freedoms from allcause mortality and from cardiac death. Presence of high-degree stenosis $(80 \%)$ appeared to influence this result.

Conclusions: In patients with triple-vessel disease undergoing first isolated coronary artery bypass grafting, supplementary venous grafts seem to provide more stability than gastroepiploic artery, which may even impair longterm outcome.

The number of coronary artery bypass grafting $(\mathrm{CABG})$ procedures is decreasing because of increased use of percutaneous coronary revascularization, especially since the advent of drug eluting stents. ${ }^{1}$ Conversely, the incidence of patients with triple-vessel coronary disease undergoing CABG has broadened remarkably in the last decade. In this scenario, surgeons must clearly identify any possible surgical strategy to improve long-term outcome. The superiority of bilateral internal thoracic artery (BITA) grafts relative to single internal thoracic artery (ITA) grafts has already been demonstrated, ${ }^{2-5}$ especially when BITA, is grafted to coronary arteries on the left side. ${ }^{45}$ The best supplementary graft for the right coronary artery (RCA) system, however, is still uncertain.

Right ITA, either in situ ${ }^{6,7}$ or Y grafted, ${ }^{8}$ does not offer any clinical or angiographic benefit relative to saphenous vein $(\mathrm{SV})$. In particular, reduced right ITA patency has been observed when grafted to distal RCA system. ${ }^{6,8} \mathrm{Al}$ though in the late 1990s some authors ${ }^{9,10}$ supported the use of radial artery (RA) as complementary conduit in cases of left-side BITA grafting, long-term angiographic results

\footnotetext{
From the Department of Cardiac Surgery, University of Catania, Catania, Italy.

Received for publication July 11, 2008; revisions received Aug 25, 2008; accepted for publication Sept 3, 2008.

Address for reprints: Antonio M. Calafiore, MD, Chief of Department of Cardiac Surgery, University of Catania, Ferarrotto Hospital, Via Citelli, 95124, Catania, Italy (E-mail: mdimauro@unich.it).

J Thorac Cardiovasc Surg 2009;137:869-74

$0022-5223 / \$ 36.00$

Copyright (c) 2009 by The American Association for Thoracic Surgery

doi:10.1016/j.jtcvs.2008.09.014
}

are still uncertain. ${ }^{11,12}$ Despite reasonable patency rate, ${ }^{13}$ the use of right gastroepiploic artery (RGEA) should be limited to graft coronary stenosis of at least $70 \%$; otherwise, the presence of an important coronary competitive flow may cause graft failure, even in patients with intact, patent grafts. ${ }^{14,15}$

To evaluate the graft of choice for revascularization of the RCA system when BITA is grafted to the left-side coronary system, this retrospective study compared long-term results of two groups of patients in which the third conduit was another arterial conduit (AC) or SV.

\section{MATERIALS AND METHODS \\ Population}

From September 1991 to December 2002, a subset of $1015(71 \%)$ of a total of 1496 patients at University of Chieti with triple-vessel coronary disease underwent first isolated CABG through a median sternotomy with BITA used for left-side myocardial revascularization. The RCA system was grafted with SV in 643 case $(63.3 \%)$ and with $\mathrm{AC}$ in the remaining $372(36.7 \%$, RGEA in 258 and RA in 114). In the first part of the analysis, RA and RGEA conduits were pooled because of similar histologic structures, ${ }^{16}$ similar reactivities to vasoconstrictor stimuli, ${ }^{16}$ and similar low patency rates when grafted onto low-grade coronary stenoses, especially on the RCA system. ${ }^{11,16}$ Further analysis was performed to evaluate separately the clinical impact of each type of AC. The three groups were similar with respect to most preoperative and operative features except for age (SV $63 \pm$ 9 years vs RGEA $60 \pm 9$ years vs RA $61 \pm 9$ years, $P<.001$ ), number of anastomoses per patient (SV $3.6 \pm 0.8$ vs RGEA $3.0 \pm 0.7$ vs RA $3.4 \pm 0.5$, $P=.005$ ), prevalence of previous acute myocardial infarction (AMI, SV $46.2 \%$ vs RGEA $58.1 \%$ vs RA $61.4 \%, P<.001$ ), prevalence of chronic renal failure (SV 3.4\% vs RGEA $0.4 \%$ vs RA $0 \%, P=.003$ ), and rate of off-pump CABG (SV $26.4 \%$ vs RGEA $17.4 \%$ vs RA $19.3 \%, P=.009$ ). 


$$
\begin{aligned}
& \text { Abbreviations and Acronyms } \\
& \begin{aligned}
\text { AC } & =\text { arterial conduit } \\
\text { AMI } & =\text { acute myocardial infarction } \\
\text { BITA } & =\text { bilateral internal thoracic artery } \\
\text { CABG } & =\text { coronary artery bypass grafting } \\
\text { CI } & =\text { confidence interval } \\
\text { ITA } & =\text { internal thoracic artery } \\
\text { RA } & =\text { radial artery } \\
\text { RCA } & =\text { right coronary artery } \\
\text { RGEA } & =\text { right gastroepiploic artery } \\
\text { ROC } & =\text { receiver operating characteristic } \\
\text { SV } & =\text { saphenous vein }
\end{aligned}
\end{aligned}
$$

A saturated regression model was solved to generate a propensity score for each patient, representing the probability of undergoing grafting with BITA plus SV. The propensity score was used to yield two propensitymatched groups by means of 2:1 sample matching; thus, a cohort of 885 patients $(87.2 \%)$ was selected from the entire population as follows: $590 \mathrm{pa}-$ tients with BITA plus SV (91.8\%) and 295 with BITA plus AC (79.3\%) (RGEA in 208 cases and RA in 87). The two subsets showed similar preoperative and operative characteristics; moreover, no statistical differences were found among patients who received RA, RGEA, and SV grafts (Table 1). These cases were included in previous publications of ours. Use of our database was authorized by the institutional review board in October 2004. This authorization waived patient consent.

\section{Surgical Technique}

A contraindication for RA harvesting was a positive Allen test result. ${ }^{17}$ RGEA was not harvested in presence of gastritis or ulcer, in cases of gallbladder calculosis, or in the expectation of further abdominal surgery. Whenever there was no contraindication to RA or RGEA harvesting, the arterial graft was chosen according to surgeon preference. Calcium blockers have been always used in patients undergoing harvest of RA or RGEA ( $60 \mathrm{mg} 3$ times/d, orally given for 6 months after the operation). The ITA was harvested in a pedicled fashion in the first 73 patients $(8.2 \%)$ and as a skeletonized conduit in the remaining $812(91.8 \%) .{ }^{18}$ BITA was used as a $\mathrm{Y}$ graft $^{19}$ in 372 cases $(42.0 \%)$, (BITA plus $\mathrm{AC}$ group $\mathrm{n}=68$, $23.1 \%$, and BITA plus SV group $\mathrm{n}=304,51.5 \%, P<.001)$. The RA and RGEA were always harvested pedicled, as previously described ${ }^{17}$; the SV was always harvested from the lower leg in a skeletonized fashion. RGEA was grafted as in situ conduit. The left anterior descending coronary artery was grafted with ITA in all cases except 23 , in which the vessel was extremely calcified or undersized and a diagonal branch was grafted instead of the left anterior descending coronary artery. RGEA was used preferably for posterior descending coronary artery grafting $(75.9 \%)$ because of its anatomic position and its usually small size. RA was mainly grafted to the RCA $(63.9 \%)$ because its size was better fitted to the RCA trunk. Most of the anastomoses performed with SV $(61.4 \%)$ were onto the posterior descending coronary artery because of the SV's caliber from being harvested from the leg. Moreover, some peripheral branches, such as retroventricular, posterolateral, and acute marginal, were included as part of the RCA. Cardiopulmonary bypass was used in 676 cases $(76.4 \%)$; myocardial revascularization was performed without cardiopulmonary bypass in the remaining $209(23.6 \%)$. The on-pump and off-pump techniques used have previously been described. ${ }^{20}$

\section{End Points}

The primary end point was any possible difference between BITA plus SV and BITA plus AC in terms of long-term outcomes: 8-year freedoms from death from any cause, cardiac death, AMI, surgical or interventional reoperation, cardiac event, and any event. Cardiac death was defined as death that was cardiac related or occurred as sudden death. Cardiac event was defined as the occurrence of at least one of following events: cardiac death, AMI, or reoperation. Any event was defined as the occurrence of at least one of the following events: death from any cause, AMI, or reoperation. Myocardial infarction was defined as enzymatic elevation, electrocardiographic sign of necrosis, new akinetic segment or segments on echocardiogram, and ventricular arrhythmias not related to potassium ion. The secondary end point was long-term clinical outcome with respect to impairment by any of the three evaluated grafts.

\section{Follow-up}

All the patients were followed up in our outpatient clinic 3, 6, and 12 months after surgery and thereafter at yearly intervals. The most recent information was obtained by calling the patient or the referring cardiologist. Follow-up was $100 \%$ complete as of June 30, 2007. Median follow-ups were 97 months (25th-75th percentiles 78-120 months) overall, 88 months (70-102 months) for BITA plus SV, and 128 months (111-142 months) for BITA plus AC (131 months, 118-143 months for BITA plus RGEA and 116 months, $80-138$ months for BITA plus RA, $P<.001$.

\section{Statistical Analysis}

Data are presented as mean $\pm \mathrm{SD}$. Statistical analysis comparing groups was performed with the Pearson $\chi^{2}$ test (or the Fisher exact test) for categoric variables. Mann-Whitney U and analysis of variance tests (with post hoc analysis) were used for comparing continuous variables in cases of two (SV vs AC) or three (SV vs RGEA vs RA) groups, respectively. All the variables initially entered in the stepwise logistic regression to generate the propensity model have been reported previously. ${ }^{20}$ The propensity score model fit and predictive power were evaluated with the Hosmer-Lemeshow goodness-of-fit (0.878) and $c$-statistic (0.901), respectively. The model was validated in 500 bootstrap samples. Eight-year survival curves were obtained with the Kaplan-Meier method; significant differences between groups were evaluated with log-rank tests. In cases of competing risks, cumulative incidences were reported. Time-to-event analysis was performed with a multivariable Cox proportional-hazard regression. Candidate variables ${ }^{20}$ were tested by univariate approach; Variables with $P \leq .2$ were entered into the Cox regression. The final model was validated in 500 bootstrap samples; factors appearing in $50 \%$ or more of the analyses were considered reliably statistically significant. The results of Cox analysis were reported as hazard ratio, $95 \%$ confidence interval $(\mathrm{CI})$, and $P$ value. The optimal cutoff degree of RCA system stenosis to predict worse 8-year cardiac mortality was determined by receiver operating characteristic (ROC) curve analysis; area under the curve with corresponding $95 \% \mathrm{CI}$ and $P$ value along with sensitivity, specificity, and their respective $95 \%$ CIs were reported. Again, the results of ROC analysis were validated in 500 bootstrap samples. The SPSS software package (SPSS Inc, Chicago, Ill) was used.

\section{RESULTS \\ Early Outcome}

Thirty-day mortality was $1.8 \%$ (16 cases); $6(0.7 \%)$ of these patients died of cardiac causes. AMI and cerebrovascular accident occurred in $11(1.2 \%)$ and $14(1.6 \%)$, respectively. The rate of aggregate negative primary end points (death from any cause, AMI, and cerebrovascular accident) was $4.0 \%$ (35 cases). Sixty-one patients $(6.9 \%)$ had a major event (death, low output syndrome, AMI, cerebrovascular accident, acute renal failure, acute respiratory insufficiency, ventricular arrhythmias, abdominal complication). Early outcome was not statistically different among groups. 
TABLE 1. Preoperative characteristics and surgical details

\begin{tabular}{|c|c|c|c|c|c|c|}
\hline & \multicolumn{4}{|c|}{ Group } & \multicolumn{2}{|c|}{$P$ value } \\
\hline & BITA + SV & BITA + AC & BITA + RGEA & BITA + RA & $1 *$ & $2 *$ \\
\hline No. of patients & 590 & 295 & 208 & 87 & & \\
\hline Age $(y$, mean $\pm S D)$ & $62.6 \pm 8.7$ & $62.1 \pm 8.0$ & $61.6 \pm 8.1$ & $63.4 \pm 7.4$ & .372 & .160 \\
\hline Female sex (No.) & $74(12.5 \%)$ & $35(11.9 \%)$ & $21(10.1 \%)$ & $14(16.1 \%)$ & .772 & .345 \\
\hline LMT disease (No.) & $89(15.1 \%)$ & $46(15.6 \%)$ & $35(16.8 \%)$ & $11(12.6 \%)$ & .843 & .647 \\
\hline $\mathrm{EF}(\%$, mean $\pm \mathrm{SD})$ & $60.6 \pm 12.8$ & $59.5 \pm 12.0$ & $59.7 \pm 12.2$ & $59.1 \pm 11.4$ & .559 & .831 \\
\hline Urgent operation (No.) & $122(20.7 \%)$ & $69(23.4 \%)$ & $54(26.0 \%)$ & $15(17.2 \%)$ & .355 & .164 \\
\hline Previous MI (No.) & $267(45.3 \%)$ & $148(50.2 \%)$ & $104(50.0 \%)$ & $44(50.6 \%)$ & .167 & .384 \\
\hline Diabetes (No.) & $126(21.4 \%)$ & $61(20.7 \%)$ & $46(22.1 \%)$ & $15(17.2 \%)$ & .816 & .629 \\
\hline COPD (No.) & $30(5.1 \%)$ & $13(4.4 \%)$ & $10(4.8 \%)$ & $3(3.4 \%)$ & .658 & .802 \\
\hline ECV (No.) & $106(18.0 \%)$ & $54(18.3 \%)$ & $36(17.3 \%)$ & $18(20.7 \%)$ & .902 & .783 \\
\hline CRF (No.) & 0 & $1(0.3 \%)$ & $1(0.5 \%)$ & 0 & .333 & .196 \\
\hline Logistic EuroSCORE (mean \pm SD) & $3.5 \pm 2.9$ & $3.1 \pm 2.8$ & $3.1 \pm 2.7$ & $3.2 \pm 3.1$ & .107 & .270 \\
\hline Additive EuroSCORE (mean $\pm \mathrm{SD}$ ) & $3.4 \pm 2.6$ & $3.3 \pm 2.4$ & $3.2 \pm 2.4$ & $3.4 \pm 2.4$ & .364 & .603 \\
\hline No. of anastomoses per patient (mean \pm SD) & $3.5 \pm 2.9$ & $3.5 \pm 0.6$ & $3.6 \pm 0.7$ & $3.4 \pm 0.6$ & .226 & .087 \\
\hline OPCAB (No.) & $149(25.3 \%)$ & $60(20.3 \%)$ & $42(20.2 \%)$ & $18(20.6 \%)$ & .183 & .176 \\
\hline
\end{tabular}

$B I T A$, Bilateral internal thoracic artery; $S V$, saphenous vein; $A C$, arterial conduit; $R G E A$, right gastroepiploic artery; $R A$, radial artery; $L M T$, left main trunk; $E F$, ejection fraction; $M I$, myocardial infarction; $C O P D$, chronic obstructive pulmonary disease; $E C V$, extracardiac vasculopathy; $C R F$, chronic renal failure; $O P C A B$, off-pump coronary artery bypass grafting. $*$ Comparison 1 is BITA + SV versus BITA + AC; comparison 2 is BITA + SV versus BITA + RGEA versus BITA + RA; no statistically significant differences were found in comparing each graft with another one.

\section{Late Outcome}

Thirty-three of 869 patients who survived the first postoperative month $(3.8 \%)$ died within 8 years after surgery; in 15 cases $(1.7 \%)$, death was cardiac related. To calculate followup event rate, patient with early events were excluded; thus, 9 of 862 patients $(1.0 \%)$ had a new AMI (7 in RCA territory). Further revascularization, either surgical or interventional, was mandatory in 13 cases $(1.5 \%), 2$ in the BITA plus AC group (1 surgical for right ITA failure, 1 interventional for RA occlusion) and 11 in the BITA plus SV group (all interventional, 2 for BITA failure, 6 for SV failure, and 3 for progression of disease). When only reinterventions for failure of graft on the RCA system were considered, 8-year freedom from reoperation was quite similar between groups $(99.0 \% \pm 0.5 \%$ in BITA plus SV group vs $99.6 \% \pm 0.4 \%$ in BITA plus AC group, $P=.367$ ), without a difference between BITA plus RA and BITA plus RGEA groups. The BITA plus SV group showed significantly higher 8-year freedoms from death from any cause and from cardiac death than the BITA plus AC group. When patients with RA and RGEA grafts were considered separately, it was evident that this difference was mainly related to RGEA grafting. All the other investigated outcome variables were not different between groups. The results are summarized in Table 2. Cumulative incidence of AMI was $2.2 \%$ in the BITA plus SV group, versus $2.1 \%$ in the BITA plus AC group $(P=$ .882 ), whereas the cumulative incidence of reoperation was $2.2 \%$ in the BITA plus SV group versus $0.7 \%$ in the BITA plus AC group $(P=.177)$. No difference was found among the three groups. Multivariable Cox proportional hazard regression confirmed that adding a supplementary RGEA graft to BITA for RCA system revascularization can impair long-term survival (hazard ratio 1.6, 95\% CI 1.1-3.1, $P=.035$ ) and cardiac survival (hazard ratio 2.9, $95 \%$ CI 1.2-6.7, $P=.017)$. Other risk factors were age, ejection fraction of $35 \%$ or less, and operative urgency. Grafting of the posterior descending coronary artery was not a risk factor.

\section{Target RCA Stenosis and Cardiac Death}

ROC curve analysis demonstrated RCA stenosis to be predictive of higher 8-year cardiac mortality (area under curve $0.81,95 \%$ CI $0.77-0.85, P=.001$ ) and identified a cutoff value of RCA system stenosis of $80 \%$ (sensitivity $100 \%, 95 \%$ CI $84 \%-100 \%$, and specificity $60 \%, 95 \%$ CI $55 \%-65 \%$ ). In the presence of RCA system stenosis less than $80 \%, 8$-year freedom from cardiac death was $98.5 \% \pm 0.8 \%$ in 205 patients with BITA plus SV, versus $89.2 \% \pm 4.2 \%$ in 56 with BITA plus RGEA, versus $100 \%$ in 25 with BITA plus RA $(P=.0001$; Figure 1). Cox analysis confirmed that the grafting of RGEA to the RCA system was a risk factor for lower freedom from cardiac death among 286 patients with RCA system stenosis less than $80 \%$. In contrast, when RCA system stenosis was at least $80 \%$, freedom from cardiac death was $98.7 \% \pm 0.6 \%$ in 385 patients with BITA plus SV, versus $98.7 \% \pm 0.9 \%$ in 152 with BITA plus RGEA, versus $96.7 \% \pm 2.3$ in 62 patients with BITA plus RA $(P=.491$; Figure 2$)$.

\section{Unmatched Analysis}

The analysis of results of the entire population before the matching process showed no statistical differences among groups with respect to early outcome. The main difference was in 8-year freedom from cardiac death between BITA 
TABLE 2. Eight-year clinical results

\begin{tabular}{|c|c|c|c|c|c|c|c|c|}
\hline & \multicolumn{4}{|c|}{ Freedom from event $(\%)$} & \multicolumn{4}{|c|}{$P$ value } \\
\hline & BITA + SV $(n=590)$ & BITA + AC $(n=2950)$ & BITA + RGE $(n=208)$ & BITA + RA $(n=87)$ & $1 *$ & $2 *$ & $3 *$ & $4^{*}$ \\
\hline All-cause mortality & $95.6 \pm 0.9$ & $91.7 \pm 1.6$ & $91.7 \pm 1.9$ & $91.9 \pm 2.9$ & .031 & .046 & .129 & .933 \\
\hline Cardiac death & $98.6 \pm 0.5$ & $95.3 \pm 1.3$ & $94.5 \pm 1.6$ & $97.6 \pm 1.6$ & .009 & .004 & .492 & .310 \\
\hline Noncardiac death & $96.9 \pm 0.7$ & $96.2 \pm 1.1$ & $97.0 \pm 1.2$ & $94.1 \pm 2.6$ & .549 & .937 & .172 & .222 \\
\hline Cardiac event & $95.9 \pm 0.8$ & $94.6 \pm 0.8$ & $94.0 \pm 1.7$ & $96.4 \pm 2.0$ & .593 & .417 & .793 & .482 \\
\hline Any event & $91.3 \pm 1.2$ & $90.7 \pm 1.7$ & $91.2 \pm 2.0$ & $89.6 \pm 3.3$ & .849 & .915 & .565 & .569 \\
\hline
\end{tabular}

Data are mean \pm SD. BITA, Bilateral internal thoracic artery; $S V$, saphenous vein; $A C$, arterial conduit; $R G E A$, right gastroepiploic artery; $R A$, radial artery. ${ }^{*}$ Comparison 1 is BITA $+\mathrm{SV}$ versus BITA + AC; comparison 2 is BITA + SV versus BITA + RGEA; comparison 3 is BITA + SV versus BITA + RA; comparison 4 is BITA + RGEA versus BITA + RA.

plus SV $(98.4 \% \pm 0.5 \%)$ and BITA plus AC $(96.3 \% \pm$ $1.0 \%, P=.043$ ); this difference was related to a higher freedom from cardiac-related death in the BITA plus SV group than in the BITA plus RGEA group $(95.6 \% \pm 1.3 \%, P=$ .030). All the other investigated late outcomes were similar among groups. In cases with RCA stenosis less than $80 \%$, 8 -year freedom from cardiac death was significantly higher in the BITA plus SV group than in the BITA plus RGEA group $(98.2 \% \pm 0.9 \%$ vs $85.2 \% \pm 4.6 \%, P<.001)$, with no difference found between BITA plus SV and BITA plus RA groups. When the RCA system showed a low-grade stenosis, 8-year freedoms from cardiac death were similar among groups.

\section{DISCUSSION}

This retrospective analysis shows that the use of RGEA for RCA system revascularization, at least in the case of BITA grafted to the left-side coronary system, may yield poorer long-term survival. This result was exclusively related to reduced long-term cardiac survival. Several studies ${ }^{2,4,5,6,13,21-24}$ have already addressed the issue of the correct graft for the RCA system from a clinical point of view. Esaki and

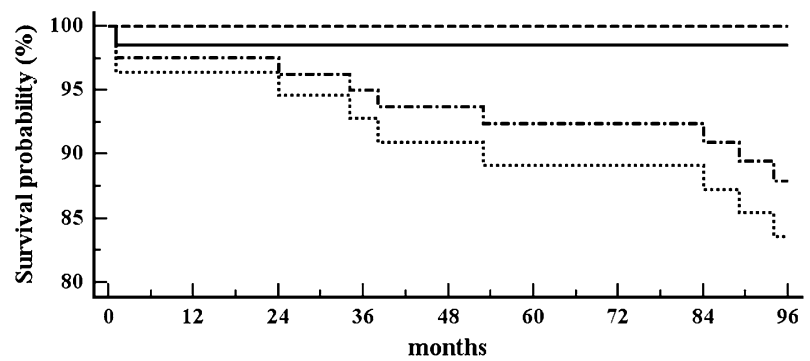

$\begin{array}{ccccccccc}\begin{array}{c}\text { Number at risk } \\ \text { Group: AC } \\ 81\end{array} & 77 & 76 & 75 & 74 & 72 & 69 & 61 & 58 \\ \text { Group: RA } & & & & & & & & \\ 25 & 24 & 24 & 24 & 24 & 23 & 21 & 14 & 13 \\ \text { Group: RGEA } & & & & & & & \\ 56 & 53 & 52 & 51 & 50 & 49 & 48 & 47 & 45 \\ \text { Group: SV } & & & & & & & & \\ 205 & 200 & 199 & 199 & 197 & 171 & 143 & 113 & 64\end{array}$

FIGURE 1. Eight-year freedoms from cardiac death for patients with right coronary artery stenosis not more than $80 \%$ with grafts of saphenous vein ( $S V$, solid line), gastroepiploic artery (dotted line, RGEA), radial artery (dashed line, $R A$ ), and arterial conduits (AC, dashed and dotted line). coworkers ${ }^{21}$ compared 99 patients undergoing grafting with RGEA with 212 undergoing grafting with SV; they found 7 -year survival, freedom from reintervention, and freedom from cardiac events to be similar between groups. On the other hand, 7-year freedom from cardiac death was higher in the RGEA-grafted group the in the SV-grafted group $(100 \%$ vs $95.5 \%, P=.032)$. Esaki and coworkers ${ }^{21}$ did not, however, include sudden deaths in the cardiac death population; moreover, patients in SV-grafted group were significantly older than those in RGEA-grafted group. Lev-Ran and colleagues ${ }^{22}$ failed to demonstrate any midterm clinical benefit of adding RGEA instead of SV to BITA (4-years survival: $91.7 \%$ for SV vs $88 \%$ for RGEA, $P=.79$ ). Again, different selection biases (such as higher rates of emergency operations and of preoperative intra-aortic balloon implants in the SV-grafted group) reduced remarkably the clinical impact seen in this study.

Looking at the literature, it is possible to state that long-term survival with BITA plus RGEA (from $88 \%$ to $91 \%)^{13,23,24}$ and with BITA plus SV (from $85 \%$ to $93 \%)^{2,4,5,6}$ are similar. Furthermore, the literature is lacking in long-term clinical comparisons of RA versus SV for RCA

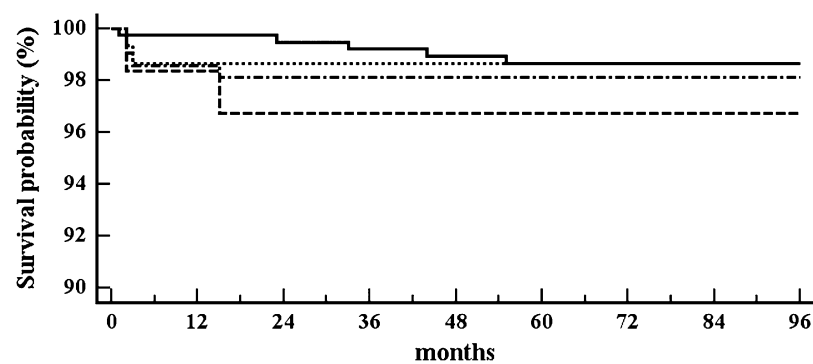

Number at risk

Group: AC

$\begin{array}{cllllllll}214 & 208 & 206 & 205 & 204 & 199 & 193 & 181 & 173 \\ \text { Group: RA } & & & & & & & & \end{array}$ $\begin{array}{ccccccccc}\text { Group: RGEA } & 60 & 58 & 58 & 58 & 56 & 52 & 44 & 42\end{array}$ $\begin{array}{rllllllll}152 & 148 & 148 & 147 & 146 & 143 & 141 & 137 & 131\end{array}$

FIGURE 2. Eight-year freedoms from cardiac death for patients with right coronary artery stenosis greater than $80 \%$ with grafts of saphenous vein ( $S V$, solid line), gastroepiploic artery (RGEA, dotted line), radial artery ( $R A$, dashed line), and arterial conduits (AC, dashed and dotted line). 
grafting. Even if RA and RGEA have different origins, with the former a limb artery and the latter a splanchnic one, they have similar histologic (muscular) structures with fenestrate internal lamina, in contrast to the ITA, which is an elastic artery. This difference in structure may explain why RA and RGEA react more strongly than ITA to vasoconstrictive substances and are more likely to have postoperative spasm. ${ }^{16}$ Moreover, RA and RGEA show similar low patency rates when grafted onto a low-grade coronary stenosis, especially on the RCA system. ${ }^{11,25,26}$ The primary end point of our study was therefore to evaluate the long-term outcomes of patients undergoing grafting with BITA plus SV versus those undergoing grafting with BITA plus AC (RA or RGEA). Although 8-year freedom from cardiac death was significantly lower in the BITA plus AC group $(95.3 \% \pm$ 1.3 vs $98.6 \% \pm 0.5 \%$ in BITA plus SV group, $P=.009$ ), further stratification by single arterial conduit demonstrated that the RGEA provided lower 8-year freedom from cardiac death than did SV grafts $(94.5 \% \pm 1.6 \%, P=.004)$. It is well known that RGEA has insufficient flow capacity ${ }^{14,25}$ and is likely to fail, even with a patent anastomosis, because of coronary competitive flow. ${ }^{15}$ Dobutamine stress echocardiography was used to evaluate the adequacy of the myocardial blood supply from the arterial graft; when the luminal diameter was greater than $2.6 \mathrm{~mm}$ (sensitivity $70 \%$, specificity $78 \%$ ), the RGEA could supply a sufficient flow under stress condition. ${ }^{15}$ Because the average internal diameter of RGEA is usually $2.2 \mathrm{~mm},{ }^{26}$ however, some authors ${ }^{25-27}$ have suggested using this graft only when the RCA system has a stenosis of at least $70 \%$ to $75 \%$.

It is now difficult to obtain routine angiographic follow-up for patients who have undergone surgical revascularization. We therefore decided to evaluate the clinical impact of a third arterial or venous graft (in addition to BITA grafting of the left-side system) according to preoperative degree of RCA system stenosis. The ROC curve identified a cutoff of RCA system stenosis that was extremely sensitive $(100 \%)$ to predict 8-year cardiac death. When RCA stenosis was less than $80 \%, 8$-year freedom from cardiac death was significantly lower in patients having RGEA grafted onto the RCA system $(89.2 \% \pm 4.2 \%$ RGEA vs $98.5 \% \pm 0.8 \% \mathrm{SV}, P=.001$, vs $100 \%$ RA, $P=.058)$. This difference disappeared when RCA stenosis was at least $80 \%(98.7 \% \pm 0.9 \%$ RGEA vs $98.7 \% \pm 0.6 \% \mathrm{SV}, P=.996$, vs $96.7 \% \pm 2.3 \% \mathrm{RA}, P=$ .350). From this subanalysis it is possible to emphasize that RGEA should be used only in cases of severe RCA stenosis, at least $80 \%$. Although in our series cardiac outcome of patients with BITA plus RA did not seem to be influenced by RCA stenosis $(P=.373)$, probably because of our small sample size, there are larger studies supporting the hypothesis that RA should be grafted onto high-degree stenosis, especially in case of RCA system grafting. Maniar and associates $^{11}$ reported on midterm angiographic patency of 231 anastomoses grafted with RA, stratified by target coronary vessel (left descending artery $83.3 \%$, circumflex system $75.2 \%$, RCA system $72.7 \%, P=.02$ ) and by coronary stenosis (moderate $57.3 \%$, severe $68.8 \%$, critical $83.0 \%, P<$ .001). Multivariate analysis confirmed that grafting of the RCA system and coronary stenosis no greater than $70 \%$ were risk factors for lower midterm cumulative patency of RA. This second finding is supported by similar studies. ${ }^{10,12}$

Concerning the SV, the relationship between its patency and native coronary artery stenosis and also the effect of flow competition on $S V$ remain controversial. ${ }^{28-30}$ In a recent report, Shimizu and colleagues ${ }^{28}$ assessed, by means of a Doppler-tipped guidewire during angiography, the graft flow volume at rest and during hyperemia in 23 RGEA and $26 \mathrm{SV}$ grafts, stratifying the results by coronary stenosis. In the presence of coronary stenosis between $50 \%$ and $75 \%$, RGEA had a flow volume roughly half that of the SV at rest and a third that during hyperthermia; moreover, RGEA flow volume was higher in stenosis greater than $75 \%$ than in moderate stenosis both at rest ( $36 \pm 17$ vs $17 \pm 11)$ and during hyperthermia (78 \pm 30 vs $32 \pm 19)$, whereas SV flow volume $(\mathrm{mL} / \mathrm{min})$ remained unchanged. In addition, Dion and associates ${ }^{7}$ reported surprisingly good patency of SV grafted onto RCA territory, similar to that of ITA, at a mean of 7.5 years after surgery. Another important issue of our study was that patients who received a third graft of AC showed lower cumulative incidence of reintervention than did patients with SV, even though this difference did not reach statistical significance. Taking into account only reintervention for failure of graft on RCA system, however, 8 -year cumulative incidence of reoperation was similar in both groups $(1.0 \%$ in BITA plus SV group vs $0.4 \%$ in BITA plus AC, $P=.412$ ). Moreover, we registered a significantly higher cumulative incidence of late sudden death in the BITA plus AC group $(1.2 \%$ vs $0.5 \%, P=.045)$, which could well be related to acute graft failure.

Our findings support a more rational use of ACs in the presence of moderate stenosis in a smaller vascular bed, as often the RCA system is. In particular, RGEA shows worse long-term results because of its inability to adapt to high competitive flow. In this case, SV seems to offer better result, probably because of its ability to maintain a good flow. ${ }^{30}$ Conversely, in presence of high-grade RCA stenosis, our 8-year outcomes were similar; very likely, however, after a longer period of observation, RA and RGEA will be seen to provide better outcomes in this subset of patients.

\section{Limitations of the Study}

The main limitation of this study is its retrospective nature. By applying propensity score and sample matching, however, we were able to reduce selection biases. The difficulty in obtaining angiographic examinations means a lack of additional information concerning the patency of the anastomoses and the functional status of the grafts, but clinical information allows a general conclusion that can 
influence the surgical strategy. Moreover, this is a historical cohort of patients who were operated on in 1990, when patients scheduled for isolated CABG showed better left ventricular function and fewer comorbidities, and thus it is less than representative of current routine CABG practice. RA seems to offer cardiac outcome similar to that of SV; however, the small sample size of patients with RA limits any conclusion in this sense. Unfortunately, the retrospective nature of the data does not provide more information on runoff status and extension of RCA system disease.

\section{CONCLUSIONS}

In conclusion, in patients with triple-vessel disease undergoing first isolated CABG, a supplementary SV graft onto the RCA system seems to provide higher long-term cardiac survival. This result can be related to the target coronary stenosis; SV yielded better results than RGEA if the stenosis was less than $80 \%$. The widespread use of antiplatelet agents and statins places the SV at lower risk for sudden occlusion, with greater likelihood of a slow progression of atherosclerotic processes.

\section{References}

1. Roiron C, Sanchez P, Bouzamondo A, Lechat P, Montalesco G. Drug eluting stents: an updated meta-analysis of randomised controlled trials. Heart. 2006; 92:641-9.

2. Lytle BW, Blackstone EH, Loop FD, Houghtaling PL, Arnold JH, Akhrass R, et al. Two internal thoracic artery grafts are better than one. J Thorac Cardiovasc Surg. 1999; 117:855-72.

3. Calafiore AM, Di Giammarco G, Teodori G, Di Mauro M, Iacò AL, Bivona A, et al. Late results of first myocardial revascularization in multiple vessel disease: single versus bilateral internal mammary artery with or without saphenous vein grafts. Eur J Cardiothorac Surg. 2004;26:542-8.

4. Pick AW, Orszulak TA, Anderson BJ, Schaff HV. Single versus bilateral internal mammary artery grafts: 10-year outcome analysis. Ann Thorac Surg. 1997;64: 599-605.

5. Dietl CA, Benoit CH, Gilbert CL, Woods EL, Pharr WF, Berkheimer MD, et al. Which is the graft of choice for the right coronary and posterior descending arteries? Comparison of the right internal mammary artery and the right gastroepiploic artery. Circulation. 1995;92(9 Suppl):II992-7.

6. Dion R, Glineur D, Derouck R, Verhelst R, Noirhomme P, El Khoury G, et al. Long-term clinical and angiographic follow up of sequential internal thoracic artery grafting. Eur J Cardiothorac Surg. 2000;17:407-14.

7. Dion R, Glineur D, Derouck D, Verhelst R, Noirhomme P, El Khoury G, et al. Complementary saphenous grafting: long-term follow-up. J Thorac Cardiovasc Surg. 2001;122:296-304.

8. Paz Y, Lev-Ran O, Locker C, Shapira I. Right coronary artery revascularization in patients undergoing bilateral internal thoracic artery grafting: comparison of the free internal thoracic artery with saphenous vein grafts. Interact Cardiovasc Thorac Surg. 2002;1:93-8.

9. Acar C, Ramsheyi A, Pagny JY, Jebara V, Barrier P, Fabiani JN, Deloche A, Guermonprez JL, Carpentier A. The radial artery for coronary artery bypass grafting: clinical and angiographic results at five years. $J$ Thorac Cardiovasc Surg. 1998;116:981-9.

10. Tatoulis J, Buxton BF, Fuller JA. Bilateral radial artery grafts in coronary reconstruction: technique and early results in 261 patients. Ann Thorac Surg. 1998;66: 714-20.
11. Maniar HS, Sundt TM, Barner HB, Prasad SM, Peterson L, Absi T, et al. Effect of target stenosis and location on radial artery graft patency. $J$ Thorac Cardiovasc Surg. 2002;123:45-52.

12. Possati G, Gaudino M, Alessandrini F, Luciani N, Glieca F, Trani C, et al. Midterm clinical and angiographic results of radial artery grafts used for myocardial revascularization. J Thorac Cardiovasc Surg. 1998;116:1015-24.

13. Nishida H, Tomizawa Y, Endo M, Koyanagi H, Kasanuki H. Coronary artery bypass with only in situ bilateral internal thoracic arteries and right gastroepiploic artery. Circulation. 2001;104(12 Suppl 1):I76-80.

14. Hashimoto H, Isshiki T, Ikari Y, Hara K, Saeki F, Tamura T, et al. Effects of competitive blood flow on arterial graft patency and diameter. Medium-term postoperative follow-up. J Thorac Cardiovasc Surg. 1996;111:399-407.

15. Ochi M, Hatori N, Fujii M, Saji Y, Tanaka S, Honma H. Limited flow capacity of the right gastroepiploic artery graft: postoperative echocardiographic and angiographic evaluation. Ann Thorac Surg. 2001;71:1210-4.

16. He GW. Arterial grafts for coronary artery bypass grafting: biological characteristics, functional classification, and clinical choice. Ann Thorac Surg. 1999;67: 277-84.

17. Calafiore AM, Di Giammarco G, Luciani N, Maddestra N, Di Nardo E, Angelini R. Composite arterial conduits for a wider arterial myocardial revascularization. Ann Thorac Surg. 1994;58:185-90.

18. Calafiore AM, Vitolla G, Iacò AL, Fino C, Di Giammarco G, Marchesani F, et al. Bilateral internal mammary artery grafting: midterm results of pedicled versus skeletonized conduits. Ann Thorac Surg. 1999;67:1637-42.

19. Calafiore Contini M, Vitolla G, Di Mauro M, Mazzei V, Teodori G, et al. Bilateral internal thoracic artery grafting: long-term clinical and angiographic results of in situ versus Y grafts. J Thorac Cardiovasc Surg. 2000;120:990-8.

20. Calafiore AM, Di Mauro M, Canosa C, Di Giammarco G, Iacò AL, Contini M. Myocardial revascularization with and without cardiopulmonary bypass: advantages, disadvantages and similarities. Eur J Cardiothorac Surg. 2003; 24:953-60.

21. Esaki J, Koshiji T, Okamoto M, Tsukashita M, Ikuno T, Sakata R. Gastroepiploic artery grafting does not improve the late outcome in patients with bilateral internal thoracic artery grafting. Ann Thorac Surg. 2007;83:1024-9.

22. Lev-Ran O, Mohr R, Uretzky G, Pevni D, Locker C, Paz Y, et al. Graft of choice to right coronary system in left-sided bilateral internal thoracic artery grafting. Ann Thorac Surg. 2003;75:88-92.

23. Tavilla G, Kappetein AP, Braun J, Gopie J, Tjien AT, Dion RA. Long-term follow-up of coronary artery bypass grafting in three-vessel disease using exclusively pedicled bilateral internal thoracic and right gastroepiploic arteries. Ann Thorac Surg. 2004;77:794-9.

24. Bergsma TM, Grandjean JG, Voors AA, Boonstra PW, den Heyer P, Ebels T. Low recurrence of angina pectoris after coronary artery bypass graft surgery with bilateral internal thoracic and right gastroepiploic arteries. Circulation. 1998;97: 2402-5.

25. Voutilainen S, Verkkala K, Jarvinen A, Keto P. Angiographic 5-year follow-up study of right gastroepiploic artery grafts. Ann Thorac Surg. 1996;62:501-5.

26. Yasuura K, Takagi Y, Ohara Y, Takami Y, Matsuura A, Okamoto H. Theoretical analysis of right gastroepiploic artery grafting to right coronary artery. Ann Thorac Surg. 2000;69:728-31.

27. Mills NL, Hockmuth DR, Everson CT, Robart CC. Right gastroepiploic artery used for coronary artery bypass grafting. Evaluation of flow characteristics and size. J Thorac Cardiovasc Surg. 1993;106:579-85.

28. Shimizu T, Suesada H, Cho M, Ito S, Ikeda K, Ishimaru S. Flow capacity of gastroepiploic artery versus vein grafts for intermediate coronary artery stenosis. Ann Thorac Surg. 2005;80:124-30.

29. Manninen HI, Jaakkola P, Suhonen M, Rehnberg S, Vuorenniemi R, Matsi PJ. Angiographic predictors of graft patency and disease progression after coronary artery bypass grafting with arterial and venous grafts. Ann Thorac Surg. 1998; 66:1289-94.

30. Urschel HC Jr, Razzuk MA, Miller E, Chung SY. Operative transluminal balloon angioplasty. Adjunct to coronary bypass for extended myocardial revascularization of more than 3000 lesions in 1000 patients. J Thorac Cardiovasc Surg. 1990;99:581-9 